\title{
Implications of Sociopolitical Context for Career Services Delivery
}

Eduardo J. R. Santos

Joaquim Armando Ferreira

Anna Chaves

This article analyzes the implications of sociopolitical context for career services delivery. Beginning with a reflection on the social foundations of the practice of career counseling, 4 specific Portuguese conditions are presented and discussed in light of existing knowledge in the field. The 4 underlying issues presented are (a) the impact of political changes on career services delivery, (b) the rigidity vs. flexibility of the educational system, (c) political and psychological perspectives on employment, and (d) the relationship between power and career services delivery. A research agenda founded in political anthropology is proposed that may enhance future career services delivery.

We begin this article with a statement: Psychology, in a broad sense, and politics should establish a common platform of theoretical thinking as well as a convergence for action. Psychology should not forget the contexts where people live, and politics should not forget that citizens are persons with specific behaviors and different life stories. In other words; we think that an interface between politics and psychology should become a concrete reality. Political psychology is a well-developed scientific field; however, cooperation between behavioral scientists and politicians needs to be deepened. Psychology needs to assume that the political structure that affects people's lives (e.g., type of regime, labor laws) is an important dimension of their life context. In addition, when, for example, politicians make laws, they must put their efforts into ensuring that those laws are representative of the people's expectations and will and that the law adjusts itself to the behavioral laws that govern people.

Both psychologists and politicians are agents of change. However, behavioral change is not possible without the understanding of life contexts,

Eduardo J. R. Santos and Joaquim Armando Ferreira are both associate professors in the Faculdade de Psicologia e de Ciências da Educafão [College of Psychology and of Education Sciences] at the University of Coimbra, Coimbra, Portugal. Anna Chapes is a doctoral student in the Department of Counseling, Depelopmental and Educational Psychology at Boston College, Boston, Massachusetts. This article was originally prepared for presentation in the symposium on setts. This article was originally prepared for presentation in the symposium on Contextual Factors in Career Service Delivery at the 106th Annual Convention of the American Psychological Association (APA), San Francisco, August 14-18, 1998. The first two authors express their gratitude to Fundação Calouste
Gulbenkian for the grants for their participation in the APA convention. The authors also thank David Blustein for his comments and belp with this article. Correspondence regarding this article should be sent to Eduardo J. R. Santos or Joaquim Armando Ferreira, Faculdade de Psicologia e de Ciências da Educafão, Universidade de Coimbra, Rua do Colégio Novo, s/n, 3000 Coimbra, Portugal (e-mail:nop37070@mail.telepac.pt; jferreira@fpce.uc.pt). 
nor is social change possible without the understanding of dimensions of the self. In a previous article (Santos \& Ferreira, 1998), we demonstrated this idea by presenting an overview of the political context of career counseling in Portugal, namely of the reciprocal interactions between individual development issues and contextual factors that affect vocational behavior. The main idea presented was that, in a context of accelerated political and social development, career counseling should act as a major foundation of "citizenship" through empowerment methodologies. In other words, career counseling, going further than the classic personenvironment fit model, should try to enhance the development of persons in a broad sense; important strategies for such enhancement are, in our view, the dimensions of creativity and social innovation. That is, career services delivery must adapt to the contexts in which it is embedded; it must not represent a static attitude but rather a more proactive posture.

The implications of sociopolitical contexts for career services delivery are not seen as being only one-way but rather are seen as being circular and existing within mutual feedback systems. Psychologists and counselors have a social responsibility to react dynamically and in a scientific manner to the tensions inherent between political context and the personal and developmental characteristics of clients. It is a two-step methodology of intervention - to facilitate adaptation to the world of work and simultaneously to enhance personal development.

This methodology may lead us to a situation in which we will finally be able to overcome one of the most challenging criticisms that, since the 1960s, has been directed at psychology. This criticism (referred to as an "ideology of replacement") focused on the belief that psychology is an instrument of social adaptation of problematic behaviors to the "status quo." There is a school of thought in the European social sciences, which is well represented by authors like Berger and Luckman (1967) and Deleule (1969), that notes that psychology does not give enough importance to the social and political dimensions of life contexts because of its excessive focus on the individual. In sum, the argument is that by looking only at the internal aspects of individual experience, the result is a biased view of human behavior as well as a biased view of society. Consistent with our theme of contextualization of behavior, we think that, in general, we need to deepen our political psychology knowledge to study the effects of social contexts on people. Simultaneously, we need to generate psychological commitment in politics, especially in the career psychology domain (Osipow, 1993).

\section{Social Foundations of the Practice of Career Counseling}

We have assumed in our preceding arguments that we need to take a critical view of the practice of career counseling. After the 1974 Portuguese revolution, it was quickly understood that education and vocational training and vocational guidance practices, in fact, consist of two related processes or factors. The first component of vocational guidance pertains to social selection and cultural reproduction, in the sense that French sociologists Bourdieu and Passeron (1970) proposed. The second refers to "self-determination" in the sense suggested presently by Blustein and Flum (1999). The first process assumes that the educational and vocational system is a tool for the reproduction of the social hierarchy, where students coming from lower economic and social classes have more probability of school and vocational failure, replicating previous fe and work paths. The second process a and vocational system is a tool that ideally foster that the educational ment and vocational satisfaction, in overcome social and economic barriers individuals are empowered to overcome social and economic barriers to have more freedom of choice and autonomy in their life and work paths.

In 1975, the Portuguese researcher Campos wrote a book titled Education Without Social Selection in which the idea of education as empowerment was central. Twenty-five years later, counselors continue to face identical problems and continue to raise the same questions. They continue to struggle with understanding how to surpass an individualistic focus of career guidance, how to embed career guidance practices in a continuous and developmental orientation into guctices in a tional training systems, how to structure educational and vocal and vocagrams in order to insert vocational goals, how to buid carecational promethodologies in a "self-deterministic" fashiow to build career education decisions with in a "self-deterministic" fashion, how to match vocational decisions with existential options and how to adjust these to the social and historical contexts, and how to enhance learning strategies in order to offer more occupational opportunities to clients. For exategies in order to lors know that cognitive abilities are based to a significante, if counseand cultural construction and value and influence of how can career counselors abilities on access to job opportunities, how can career counselors compensate for this phenomenon via their array of intervention strategies? In other words, how do they infuse vocational goals into compensatory educational methodologies (e.g., Reynolds
\& Gutkin, 1999)?

These are questions that are raised persistently because, in our view, endeavors in the fields of vocational psychology and career counseling are extremely challenging and difficult ones. Solutions are counseling find, but we think that if career counselors confront social matter must, indeed, generate first a profound analysis and social foundations of The foundations of their models and practices.

The classic work of Vondracek, Lerner, and Schulenberg (1986) offered an epistemological grid that permits us to combine human developmental issues and the contextual issues. Regarding the specific theme of this article, Vondracek et al. quoted from Bronfenbrenner, who pointed out that a revision of the relationships between public policy and basic science is needed (p. 42). These authors also referred to the work of Krumboltz (1981), who pointed out a sample of public-policy-related environmental conditions that affect career development (e.g., social policies of selection of workers, labor laws, the educational system). Vondracek et al. concluded that career counselors need to have, according to Bronfenbrenner's (1979) conceptualization, a functional integration of public policies and science procedures, or "interconnectedness" between these areas.

Although career counselors are beginning to develop epistemological models of analysis (e.g., developmental-contextualism), it is difficult to find systematic scientific production in this area. Career counselors can, 
however, find some interesting research, like that presented by Pfeffer (1989), about political perspectives on careers in organizational contexts; this work stressed the interplay between interests and power networks and its influence in human resource management procedures. In his introductory statements, Pfeffer (1989) stated

Although individual choices and strategies are important and efficiency concern do have some role in explaining organizational arrangements and individual decisions, the current preoccupations overlook some important considerations for understanding careers and career processes. This chapter develops a more ind a more policical and sociological focus, anguing for the imp the analysis used to answer them. (p. 380)

In the politics and standards of hiring, in the way recruitment and job search interconnect, in the shape of the internal labor markets and job classifications within the mobility structures of the organizations, and in the politics of wages and succession, Pfeffer (1989) identified important contexts for the understanding of careers in organizations. This approach is essential to a new view of careers. Quoting Pfeffer (1989) again, we are able to better understand his point of view:

Concepts such as cohorts (Pfeffer, 1983; Stewman \& Konda, 1983) and network ideas that emphasize the interconnections among people, both in helping each other as in recruitment and in the zero-sum competition for status and promotions, are essential. (p. 393)

In a more universal way, Herr (1996b) presented a look at the future trends in career guidance concerning the social shifts that are expected for the next century. With the danger of being too simplistic, psychosocial dimensions of personal flexibility and career motivation could become the general target behaviors that counselors stimulate in their clients (see also Herr \& Cramer, 1992). However, it should not be forgotten that there are complex and specific characteristics in each particular social and career setting. In fact, Herr (1996b) did not ignore such realities. For example, he noted that different ways of funding career services (state vs. private) led to different counseling practices in such domains as the counselor's freedom and autonomy to apply more personalized techniques, and not just the standardized procedures that exist in every organization. Universality and, paradoxically, diversity will bring us growing difficulties at the same time (see also Häyrynen, 1996; Watts, 1996a). In a special section of an issue of The Career Development Quarterly, varied authors (Bloch, 1996; Harris-Bowlsbey, 1996; Herr, 1996a; Lent, 1996; Savickas, 1996; Watts, 1996b) discussed the realities of diversity and globalization and the importance of individuality and specificity of persons and groups in relation to the diffusion of general models and techniques.

More specifically, Herr (1996a), Bloch (1996), and Watts (1996b) have provided some insight and direction about the future of career counseling in their descriptions of the important changes that are occurring in the ecological context of vocational guidance, the structure of the world of work, and in social policy related to career services. Lent (1996) eloquently summarized this look into the future when he stated that a different metaphor and set of roles has to be envisioned, that is, a view of counseling and guidance as linchpins in the processes of work prepato anticipate and negotiate passages to and between career settings. (p. 64)

In confronting the challenges of this century, then, convergence is being reached regarding the main goals for career services delivery. As we noted previously, the diffusion of general and global models and techniques is occurring. Yet, we question whether this is sufficient and whether it will be responsive to local problems and cultures. It is important to recall that, from a political point of view, career counselors are witnessing the renall that, from regionalism and the increasing affirmation of cultures. What do they need to solve these problems? In sum, they must analyze the future trends of the world of work and the social foundations of vocational behavior. In this way, they will be better able to plan career services delivery and to adapt it to the specific sociopolitical contexts.

To synthesize, career counselors have new universal vocational constructs (e.g., personal flexibility, career motivation) that oblige them to think about new forms of career services delivery. At the same time, regional political systems, local cultures, and specific social and career phenomena are in contrast to the globalization phenomena. In and career personal flexibility as a universal challenge and eer counselors may acquire different me and behavioral target for ca(see also, e.g., Barnes-Farrell, 1993).

Career counselors also must open different fronts of research to inform their practice. A possibly productive pathway is one that combines (a) more global and structuralist approach, (b) segmental models of (a) tional behavior (e.g., Super's, 1990, 1994, Archway Model of Career Determinants), and (c) more qualitative and case-study analyses to test both prior approaches and models. Consequently, in the following sections, we present four cases taken from the Portuguese experience and apply existing knowledge to these specific Portuguese experience and first case addresses the impact of political Portuguese conditions. The delivery, the second addresses the rigidity versus flexibility of the educational system, the third addresses political and psychological perspectives on employment, and the fourth addresses the relationship between power and career services delivery.

\section{Case 1: Impact of Political Changes of Career Services Delivery}

This first case concerns the impact of a rapidly changing political structure on career services delivery. In Portugal, the political system is a democracy, but a rather young demortical system is a lived under a fascist regime. This radical political compassed a change to a high level of freedom and person naturally enone's decision make to a high level of freedom and personal volition in One's decision making. From an existential point of view, according to Yalom's (1980) psychodynamic model, freedom means openness to decision making, responsibility, and individual choices. Freedom, with its vast array of options, however, brought enormous challenges to people who sometimes struggled with responsibility avoidance and considerable internal and external barriers. Growth in career indecision and decisional 
conflict were the main expressions of these rapid and radical shifts in the political structure in the country (Santos, Ribeiro, \& Campos, 1997).

Re suggest that a way to counterbalance the impact Regarding this case, we strategies of career exploraof this sociopolitical context is to reinforce the and Blustein, Phillips, Jobintion within career services. Blustein (1997) and Blustein, Davis, Finkelberg, and Roarke (1997) stated the importance of exploration in the school-to-work transition. According to these authors, the stimulation of exploration attitudes and competencies leads to more intrinsically lation of explore motivated vocationalibity are enhanced if career counselors provide people maturity and adaptability are enhanced if career counselors information, eswith coping strategies to gather and process occupational information pecially when the environment is not "friendly" in this dimension. \& Hackett, 1996; Lent, Hackett, \& Brown, 1997) also provides a fundamental tool for intervention. Stimulating learning experiences through mental to vocational behaviors in experiential activitios to expansive a context in which the flow and diversity of information is too expansive to handle only in "introspective ways." Person inputs, background con textual affordances, learning experiences, self-efficacy processes, outcome expectations, interests, choice goals, choice actions, performance do expectations mains and attainments, and contex social learning model. Following havior are the mancer, a counselo the tradition of the learning models of vocational behavior, a counselo must then turn these dimensions into concrete fields of intervention.
Following the ideas of Blustein and collaborators, activation of explora ion behavior is a good way to define interests in a more concrete and tion behar emerging adjusted way (Blustein \&cFun behavior is not a mere psycholgical perspective that control of human bex interaction between function of information processing but is a complex interaction between cognition and action (Lord \& Levy, 1994). In the language of vocational

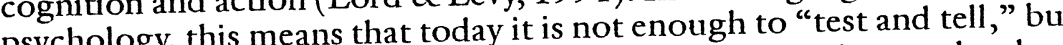
psychology, this means that tod stimulate learning experiences that lead rather career counselor more

people to the elaboration of occupation
adjusted to the modern world of work.

\section{Case 2: Rigidity Versus Flexibility of the}

\section{Educational System}

A second relevant sociopolitical issue is that the educational and vocaA second relevant sociopolitical issue is that the major decisions, often well tional training system forces student choices. Developmental theory ( $\mathrm{Su}$ before they are prepared for such choices. Developmental theory (Super, Savickas, \& Super, 1996) states that by age 15 , adolescents should be exploring. In the Portuguese educational system, however, students at this age are obliged to make early choices in high school between major this age are obliged to make eart repercussions for subsequent choices besets of courses. This has vast open to young percause the choices made at that anch sons later. For example, the choice of the humanistic studies branch in high school makes it impossible for an adolescent to change later to a more scientific or technological area. The Portuguese educational system, thus, is organized in a way inconsistent with what is known about the thus, is organized in a wat development. That is, it requires young process of adolescent vocational development. That is, it requires young persons to make early and important educational decisions that affect their life or career trajectory. The adolescent is confronted with choices when in psychological terms he or she is still in a process of vocational identity formation.

This mismatch is a good demonstration of the eventual conflict or antagonism that may happen between social policies and scientific knowledge and practice. In this case, we think that a strong intervention would require the placement of psychologists near the political institutions to promote meaningful changes in the way the educational system is structured. Despite this educational context, however, career counselors must answer to the needs of clients. Thus, career services delivery must be concerned with the negative impact of such threats on the vocational identity development process, embedding personal counseling activities in the overall intervention. The new alternatives presented by the constructivist career counseling models and methods (Savickas, 1997) represent one good option for intervention. Furthermore, if the context (e.g., educational system) is not planned according to models of lifelong human development, then vocational professionals must become proactive. This may require a political commitment from counselors and researchers to discover and adopt new and effective models of intervention.

Finally, in such a context as we have described, professionals must be concerned with the personal construction of work meanings rather than with a strictly vocational adjustment perspective. Beyond educationa constraints, adolescents must learn how to find interests, satisfactions, and motivations within the world of work, independent of the solutions found for their career problems. In the end, adolescents must find a way to express their occupational self-concepts no matter the configurations of the world of work. A more subjective approach to decision making, choices, and implementation of career plans (Brêda, 1996) must be the focus of career services delivery in situations like the one just described. A good example is the match between work and leisure activities that, in our opinion, must be encouraged in career and vocational education programs.

\section{Case 3: Political and Psychological Perspectives}

\section{on Employment}

The third case we present pertains to the global problem of unemployment, which has a particular set of unique characteristics in the Portuguese culture. Generally, unemployment is conceptualized primarily from a remedial perspective (e.g., finding a new job) and not from a developmentalvocational point of view (e.g., finding a new job with a new persona meaning). In the evaluation of the outcomes of these kinds of interventions, relapses are frequent with unemployed clients, with many of these clients becoming long-term unemployed individuals.

This is the context in which career counselors often work with the unemployed. Yet current thinking is that they must have "lifelong strategies" of career counseling to cope with the constant change and evolution in the world of work. In the specific domain of intervention with adults, they are convinced that prevention and treatment strategies must be organized and developed around the maintenance of the psychological 
Bloch, D. P. (1996). Career development and work force preparation: Educational policy versus school practice. The Career Development Quarterly, 45, 20-40.

Blustein, D. (1997). A context-rich perspective of career research exploration across the life roles. The Career Depelopment Quarterly, 45, 260-274.

Blustein, D., \& Flum, H. (1999). A self-determination perspective of exploration and interests in career development. Manuscript submitted for publication.

Blustein, D. L., Phillips, S. D., Jobin-Davis, K., Finkelberg, S. L., \& Roarke, A. E. (1997). A theory-building investigation of the school-to-work transition. The Counseling Psychologist, 25, 364-402.

Bourdieu, P., \& Passeron, J. C. (1970). La réproduction. Paris: Ed. Minuit.

Brêda, M. S. (1996). Trabalho e vocaçāo [Work and vocation]. Unpublished master's thesis, University of Coimbra, Coimbra, Portugal.

Bronfenbrenner, U. (1979). The ecology of human development. Cambridge, MA: Harvard University Press.

Campos, B. P. (1975). Educaf̧ão sem seleç̧ão social [Education without social selection]. Lisboa, Portugal: Livros Horizonte.

Deleule, D. (1969). La psychologie: Mythe scientifique [Psychology: Scientific myth] Paris: Robert Laffont.

Harris-Bowlsbey, J. (1996). Synthesis and antithesis: Perspectives from Herr, Bloch, and Watts. The Career Development Ouarterly, 45, 54-57.

Häyrynen, Y. (1996). The future of guidance and battle of modern self. Bulletin of International Association for Educational and Vocational Guidance, 58, 23-29.

Herr, E. L. (1996a). Perspectives on ecological context, social policy, and career guidance. The Career Development Quarterly, 45, 5-19.

Herr, E. L. (1996b). Trends in career guidance theory and practice and the effects of social context and individual reactions to it. Bulletin of International Association for Educational and Vocational Guidance, 58, 33-49.

Herr, E. L., \& Cramer, S. H. (1992). Career guidance and counseling through the lif span: Systematic approaches (4th ed.). New York: Harper Collins.

Krumboltz, J. D. (1981). A social learning theory of career selection. In D. H. Montross \& C. J. Shinkman (Eds.), Career development in the 80's: Theory and practice (pp. 43-66). Springfield, IL: Thomas.

Lent, R. W. (1996). Career counseling, science, and policy: Revitalizing our paradigms and roles. The Career Development Quarterly, 45, 58-64.

Lent, R. W., Brown, S. D., \& Hackett, G. (1996). Career development from a social cognitve perspective. In D. Brown \& L. Brooks and Associates, Career choice and development (3rd ed., pp. 373-422). San Francisco: Jossey-Bass.

Lent, R. W., Hackett, G., \& Brown, S. D. (1997, August). School-to-work transition and social cognitive career theory. In Applying vocational psychology theories to the school-to-work transition. Symposium conducted at the American Psychological Association convention, Chicago.

Lord, R. G., \& Levy, P. E. (1994). Moving from cognition to action: A control theory perspective. Applied Psychology: An International Review, 43, 335-366.

Loureiro, R. M. (1997). Vinculaf̧ão e desenvolvimento vocacional: um estudo empírico sobre os padröes de vinculaf̧ão como preditores das estratégias de confronto no desemprego involuntário [Attachment and vocational development: An empirical study of attachment styles as predictors of the coping strategies on involuntary unemployment]. Unpublished master's thesis, University of Coimbra, Coimbra, Portugal.

Marko, K. W., \& Savickas, M. L. (1998). Effectiveness of a career time perspective Marko, K. W., \& Savickas, M. L. (1998). Effectiveness of a care
intervention. Journal of Vocational Behavior, 52, 106-119.

Osipow, S. H. (1993, August). Toward mainstreaming the study of career psychology: Overcoming the Rodney Dangerfield effect. Paper presented at the Third International Symposium on Career Development, University of Toronto, Canada.
Pfeffer, J. (1983). Organizational demography. In L. L. Cummings \& B. M. Staw (Eds.), Research in organizational behavior (Vol. 5). Greenwich, CT: JAI Press.

Pfeffer, J. (1989). A political perspective on careers: Interests, networks, and environments. In M. B. Arthur, D. T. Hall, \& B. S. Lawrence (Eds.), Handbook of career theory (pp. 380-398). Cambridge, England: Cambridge University Press.

Reynolds, C. R., \& Gutkin, T. B. (1999). The handbook of school psychology (3rd ed.). New York: Wiley.

Santos, E. R., \& Ferreira, J. A. (1998). Career counseling and vocational psychology in Portugal: A political perspective. Journal of Vocational Behavior, 52, 312-322. Santos, C., Ribeiro, L., \& Campos, P. (1997). A promoção do desenvolvimento vocacional dos alunos-uma aposta da escola: A experiência de uma comunidade educativa [Promoting students' vocational development: The experience in an educational community]. In APPORT/COP (Eds.), Actas do $1^{\circ}$ Congresso Luso-Espanbol de Psicologia da Educą̧ão, Coimbra, Portugal.

Savickas, M. L. (1996). Public policy and career counseling for the twenty-first century. The Career Development Quarterly, 45, 3-4.

Savickas, M. L. (1997). Constructivist career counseling: Models and methods. In G. J. Neimeyer \& R. A. Neimeyer (Eds.), Advances in personal construct psychology (Vol. 4, pp. 149-182). Greenwich, CT: JAI Press.

Stewman, S., \& Konda, S. L. (1983). Careers and organizational labor markets: Demographic models of organizational behavior. American Journal of Sociology, 88,
$637-685$.

Super, D. E. (1990). A life-span, life-space approach to career development. In D. Brown \& L. Brooks and Associates (Eds.), Career choice and development (2nd ed., pp. 197-261). San Francisco: Jossey-Bass.

Super, D. E. (1994). A life-span, life-space perspective on convergence. In M. L. Savickas \& R. W. Lent (Eds.), Convergence in career development theories (pp. 63-74). Palo Alto, CA: Consulting Psychologists Press.

Super, D. E., Savickas, M. L., \& Super, C. M. (1996). The life-span, life-space approach to careers. In D. Brown \& L. Brooks and Associates (Eds.), Career choice and development (3rd ed., pp. 121-178). San Francisco: Jossey-Bass.

Vondracek, F. W., Lerner, R. M., \& Schulenberg, J. E. (1986). Career depelopment: A life-span development approach. Hillsdale, NJ: Erlbaum.

Watts, A. G. (1996a). A framework for comparing careers guidance systems in different countries. Bulletin of International Association for Educational and Vocational Guidance, 58, 53-63.

Watts, A. G. (1996b). Toward a policy for lifelong career development: A transatlantic perspective. The Career Development Quarterly, 45, 41-53.

Yalom, I. D. (1980). Existential psychotherapy. New York: Harper Collins. 